\title{
Preparação e uso de polímeros sólidos como eletrólito em sensores de hidrogênio
}

\author{
Preparation and employ of solid electrolyte \\ polymer electrolyte for hydrogen sensors
}

Otávio Carneiro Corrêa, José A.C.Ponciano Gomes

\author{
${ }^{1}$ Laboratório de Corrosão - PEMM/COPPE/UFRJ - Rio de Janeiro - RJ \\ e-mail: occorrea@metalmat.ufrj.br; ponciano@metalmat.ufrj.br
}

\section{RESUMO}

A detecção de hidrogênio permeado através de estruturas metálicas é tema de grande relevância, tendo em vista monitorar e controlar os danos que o hidrogênio causa nos metais, em especial o aço. Existem diversas tecnologias aplicadas à montagem destes sensores como, por exemplo, os sensores eletroquímicos.

Muito usados em pilhas a combustível, membranas poliméricas vêm sendo empregadas como alternativa ao eletrólito líquido em sensores eletroquímicos por diversas razões, como: resistência à deterioração e durabilidade. Existem diversos tipos que possuem as características para este fim, porém o mais empregado é o Nafion®. A principal característica destes polímeros é sua condutividade protônica causada pela dissociação das moléculas de água presentes em sua estrutura. Sendo assim, a sua condutividade é fortemente dependente da quantidade de água contida no material. A temperatura é outra variável que pode influenciar na condutividade protônica.

Foi feita uma revisão destas variáveis e das técnicas que podem ser empregadas na preparação de polímeros para se obter as propriedades desejáveis. A análise inicia com a discussão do método de preparação, limpeza inicial, hidratação e acondicionamento do polímero hidratado. Com este trabalho espera-se obter uma diretriz para a preparação de um polímero para uso como eletrólito sólido, suas características e propriedades e assim, aplicá-lo ao desenvolvimento de um sensor eletroquímico de hidrogênio.

Palavras-chave: hidrogênio, sensores, polímeros condutores de prótons, eletrólitos sólidos.

\section{ABSTRACT}

The permeated hydrogen detection through a metal membrane is essential to monitoring and control of hydrogen damage, especially in steels. Among several sensors technologies available, the electrochemical sensors are widely used.

Solid polymer electrolytes (SPE), used in Solid Polymer Electrolyte Fuel Cells (SPEFC), can be an alternative to replace liquid electrolyte in electrochemical sensor, due its chemical and mechanical stability. There are several polymers used in this application, although the standard one is Nafion®. The most important characteristic of a SPE is the proton conductivity, caused by water molecules dissociation in the structure of the polymer. Consequently, the conductivity is highly dependent on membrane humidification conditions. Temperature can also influence the proton conductivity.

In this work, we review the SPE characterization and its treatment techniques. We discuss also preparation, hydration and storage of a polymer to be employed in construction of a hydrogen electrochemical sensor.

Keywords: Hydrogen, Hydrogen Sensors, Solid Polymer Electrolytes, Proton Exchange Membranes.

\section{INTRODUÇÃO}

Os problemas relacionados à permeação de hidrogênio em metais são amplamente conhecidos e difundidos, bem como algumas técnicas de monitoramento. Porém, ainda existe a necessidade de se desenvolver um sensor de hidrogênio confiável e de baixo custo para aplicação industrial.

Já bastante empregados em pilhas a combustível, as membranas poliméricas, como por exemplo, o Nafion®, 
podem ser uma alternativa viável para uso como eletrólito sólido em sensores eletroquímicos de hidrogênio. A possibilidade desta aplicação se dá pelas características deste polímero, como a condutividade protônica, resistência mecânica e química e durabilidade.

Neste trabalho será feita uma revisão bibliográfica sobre as características deste polímero, os parâmetros desejáveis para seu uso como eletrólito sólido, alguns métodos de preparação e os exemplos de aplicação do Nafion ${ }^{\circledR}$ na detecção de hidrogênio, visando criar uma base de conhecimento para futura aplicação deste tipo de membrana em sensores de permeação de hidrogênio em metais.

\section{MATERIAIS E MÉTODOS}

\subsection{Danos pelo hidrogênio e seu monitoramento}

A interação de hidrogênio com metais, sobretudo o aço, é um tema de grande relevância em pesquisas e desenvolvimento. Os mecanismos de interação do hidrogênio com metais e suas causas, embora objeto de muitas pesquisas, ainda apresentam pontos importantes a serem esclarecidos. De toda maneira, é de consenso geral que a fragilização por hidrogênio causa a perda de propriedades mecânicas de metais pela penetração e retenção de hidrogênio, podendo levar a falhas prematuras do material. É possível constatar este fato de diversas formas, com diferentes mecanismos de ruptura e a partir de várias fontes de hidrogênio.

Dos setores industriais, os que mais apresentam relatos sobre o problema são os de produção, transporte e refino de óleo e gás. Neste setor, questões econômicas, de segurança, continuidade operacional e controle acentuam a preocupação com o fenômeno. Portanto, o emprego de soluções de monitoramento da permeação de hidrogênio em aços é uma necessidade.

Um grande esforço de pesquisa e desenvolvimento tem apresentado inúmeras tecnologias de detecção de hidrogênio em metais. Todavia, ainda há uma grande demanda de aprimoramento de sensores de permeação de hidrogênio e de seus equipamentos periféricos. O principal problema encontrado na prática é como quantificar, de modo seguro, rápido e economicamente viável, a permeação de hidrogênio em um material sujeito a um meio corrosivo gerador de hidrogênio, de modo a utilizar medidas de controle para evitar os danos que podem ser causados [1].

\subsection{Histórico da tecnologia de deteç̧ão de hidrogênio}

De acordo com JAMBO et al. [2] a detecção de hidrogênio teve seus primeiros dispositivos desenvolvidos na década de 60 . Com o crescente interesse pelo estudo da fragilização pelo hidrogênio ligado diretamente à indústria do petróleo, recentemente, a aplicação de sensores viáveis para medições em campo se tornou uma necessidade.

Sendo assim, diversos dispositivos foram desenvolvidos recentemente para este fim. JAMBO [3] divide os dispositivos de medição de permeação de hidrogênio utilizáveis em campo, em três grandes grupos: sensores de pressão, sensores a vácuo e sensores eletroquímicos.

Atualmente, com a demanda crescente em se desenvolver fontes de energia alternativa, o hidrogênio tem ganhado destaque como sendo uma opção viável. Para o desenvolvimento de geração de energia a partir do hidrogênio, são necessários meios de detecção para diversos fins, como segurança e monitoramento. A partir dos anos 2000, alguns modelos de sensores de hidrogênio empregando outras tecnologias, como fibras óticas [4] ou pilhas a combustível [5], foram apresentados.

Com o objetivo de determinar os coeficientes de difusão do hidrogênio em metais, DEVANATHAN et al. [] desenvolveram uma técnica eletroquímica na década de sessenta que era capaz de medir a intensidade da permeação de hidrogênio. Esta técnica ainda continua sendo referência básica para os sensores eletroquímicos de hidrogênio.

Sensores eletroquímicos de paládio, níquel [7], Barnacle Cells [] e outros foram desenvolvidos para a aplicação em campo com a característica comum de utilizar o princípio de funcionamento da técnica de DEVANATHAN et al. [6]. Todos estes tem também em comum o uso de eletrólitos líquidos, sujeitos à degradação, o que prejudica sua durabilidade e aplicação em campo [5].

Alguns autores propõem sensores baseados em polímero sólido, como é o caso do trabalho de LYON et al. [9]. Sensores baseados no princípio de funcionamento de pilhas a combustível foram propostos também utilizando polímeros sólidos como eletrólito [5, 10]. Muitos sensores que utilizam eletrólitos sólidos têm bons resultados na medição de misturas de gases contendo hidrogênio. Porém, na literatura encontram-se poucos trabalhos com resultados representativos da permeação de hidrogênio em metais em comparação com a 
técnica de DEVANATHAN et al. [్]. Ng e Newman [5] compararam sensores de hidrogênio eletroquímicos baseados em eletrólitos sólidos com o ensaio de DEVANATHAN et al. [] e obtiveram a relação das curvas de permeação de hidrogênio em regime permanente entre eles.

\subsection{Polímeros Sólidos como Eletrólito}

Desde o advento das pilhas a combustível, que tiveram suas primeiras apresentações por volta de 1840 , busca-se um eletrólito condutor de prótons estável, durável e de baixo custo para a aplicação [11]. O uso de eletrólitos sólidos se tornou comum em pilhas a combustível, sobretudo com o desenvolvimento do copolímero Perfluorosulfônico/PTFE estabilizado, produzido pela DuPontTM sob o nome comercial de NAFION $®[12]$. Outros polímeros também são muito estudados como alternativa para uso como eletrólito sólido [13].

Há alguns anos, diversos estudos empregando polímeros como eletrólito em sensores de hidrogênio vêm sendo publicados, desde sensores de hidrogênio gasoso [14] a sensores eletroquímicos amperométricos e potenciométricos []].

As características necessárias ao emprego de eletrólitos sólidos em sensores de hidrogênio são as mesmas inerentes ao uso em pilhas a combustível: alta condutividade protônica, estabilidade química, resistência e durabilidade, além do custo.

\subsection{Características Desejáveis aos Eletrólitos Sólidos}

\subsubsection{Condutividade Protônica}

A condutividade protônica é a propriedade central dos polímeros para que sejam utilizados como eletrólito sólido em pilhas a combustível ou sensores de hidrogênio. Esta propriedade mede a capacidade que o polímero tem de conduzir os prótons $\mathrm{H}+$ através de sua estrutura.

A condutividade e, portanto, o desempenho de uma membrana polimérica dependem fortemente da quantidade de água contida na estrutura do polímero [15]. Os polímeros em seu estado desidratado possuem condutividade considerada nula para sua aplicação. GAVACH et al [16] estabelecem que a condutividade de membranas de NAFION® é aumentada quando há uma proporção maior que seis moléculas de água por grupo de ácido sulfônico.

Basicamente, a medição da capacidade de condução protônica de uma membrana polimérica é realizada por ensaios de impedância eletroquímica. Diversos autores $[\underline{11}, \underline{13}, \underline{15}]$ estudaram a condutividade protônica de certos polímeros, em especial o NAFION®, em função de sua condição de hidratação, usando a técnica de impedância.

A temperatura também é uma variável que influencia a condutividade de uma membrana condutora de prótons [17], conforme demonstra Barbir [17].

A Tabela mostra a relação da condutividade protônica de uma membrana polimérica em função da quantidade de água e da temperatura, compilada de resultados de alguns estudos $[\underline{15}, \underline{17}]$.

Tabela 1 - Relação de parâmetros com a condutividade protônica de uma membrana polimérica.

\begin{tabular}{c|c}
\hline Parâmetro & Condutividade Protônica \\
\hline Quantidade de água & Diretamente Proporcional \\
\hline Temperatura & Diretamente Proporcional \\
\hline
\end{tabular}

\subsubsection{Absorção de Água}

Muitas das propriedades de polímeros utilizados como membranas para pilhas a combustível e, no caso, sensores de hidrogênio, estão diretamente ligadas à quantidade de água absorvida pela estrutura polimérica. É comum quantificar-se certas características, como é o caso da condutividade, em função da condição de hidratação do polímero. Propriedades mecânicas e morfológicas também podem ser afetadas pela quantidade de água.

Medidas de quantidade de água absorvida pelos polímeros são feitas pelo ganho de massa de uma amostra totalmente seca da membrana ou então, pelo equilíbrio de uma amostra contendo água e uma conhecida umidade relativa [11], em uma temperatura constante. ANANTARAMAN et al. [15] mostraram que quanto maior a umidade relativa do meio em que se encontra a membrana, maior é a quantidade de água absorvida por esta. 
O transporte de água na estrutura da membrana também é importante, sobretudo em pilhas a combustível em operação, pois a manutenção da hidratação é fundamental para manter as características de condutividade e, desta maneira, sua eficiência.

\subsubsection{Estabilidade Térmica, Mecânica e Química}

Dado que algumas propriedades, como por exemplo, a condutividade de membranas, e, no caso de pilhas a combustível, a eficiência energética, cinética eletroquímica e resistência a contaminações são dependentes da temperatura, então, a operação em temperaturas mais altas é benéfica para as membranas condutoras de prótons e, por consequência, às pilhas a combustível e sensores de hidrogênio [18]. Porém, segundo COLLIER et al. [18], a degradação das membranas poliméricas é maior para temperaturas mais altas. No caso do NAFION®, a partir de $150^{\circ} \mathrm{C}$ nota-se que a estrutura química começa a ser afetada [18]. Segundo os mesmos autores, ciclos térmicos, variando entre altas e baixas temperaturas, também aceleram a degradação dessas membranas.

A temperatura de operação de pilhas a combustível de membrana polimérica é geralmente menor do que $80^{\circ} \mathrm{C}$, o que não impõe problemas ao uso de membranas poliméricas diversas. Todavia, durante operações pontuais, como o pré-tratamento das membranas ou ciclos térmicos, temperaturas maiores podem ser atingidas, sendo as causas de falhas prematuras [18]. Para uso em sensores de hidrogênio, a aplicação em temperaturas de até $75^{\circ} \mathrm{C}$ abrange boa parte dos possíveis equipamentos a serem monitorados [ [ $]$.

A estabilidade mecânica também é uma propriedade importante das membranas condutoras de prótons. Segundo COLLIER et al. [18], a degradação mecânica destas membranas pode ocorrer durante o processamento, a montagem e a operação, podendo levar a falhas prematuras. O procedimento de preparação destas membranas, bem como a montagem, deve ser rigorosamente estudado para evitar tensões locais, pressões excessivas e choques, evitando-se assim a degradação mecânica dos polímeros.

COLLIER et al. [18] fizeram uma compilação bibliográfica em torno da degradação química e eletroquímica de membranas utilizadas em eletrólitos sólidos. Puderam, então, concluir que a estabilidade química e eletroquímica destas membranas é afetada principalmente por ataques de radicais formados durante o processamento e a operação. Contaminantes metálicos aceleram a formação destes radicais [18].

No caso de pilhas a combustível de metanol, a absorção deste pela membrana é um parâmetro importante a ser notado, estando diretamente ligado à eficiência da célula e a estabilidade do eletrólito sólido [11].

\section{NAFION® 117 E SUA PREPARAÇÃO}

\subsubsection{Nafion® 117}

Dos diversos tipos de polímeros utilizáveis na fabricação de membranas condutoras de prótons para uso como eletrólito sólido, o mais amplamente empregado e com maior disponibilidade comercial é o Nafion ${ }^{\circledR}$, fabricado pela DuPontTM. Sua cadeia é um copolímero onde uma das unidades monoméricas é o tetrafluoroetileno (TFE) e o comonômero é uma cadeia lateral éter vinila perfluorada com grupos sulfônicos nas terminações [19]. A cadeia está representada na Figura 1.

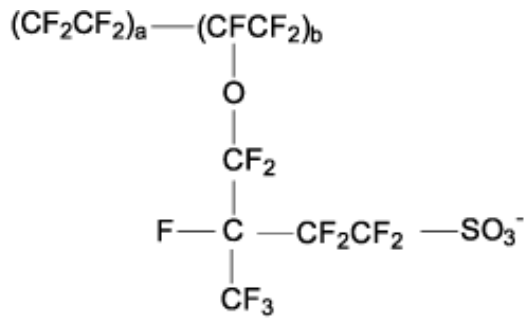

Figura 1 - Cadeia polimérica do Nafion ${ }^{\circledR}$

O Nafion® está disponível em soluções poliméricas com diferentes concentrações ou em membranas (filmes) extrudados, com diferentes espessuras. O Nafion ${ }^{\circledR} 117$ corresponde à membrana extrudada com $178 \mu \mathrm{m}$ de espessura [12].

Diversos autores $[\underline{5}, \underline{13}-\underline{15}, \underline{20}]$ estudaram membranas de troca protônica baseadas em Nafion ${ }^{\circledR} 117$, muitas delas aplicadas em tecnologias de deteç̧ão de hidrogênio. Com base nestes estudos, este trabalho faz uma revisão sobre métodos de preparação e aplicação deste material. 


\subsubsection{Tratamento da Membrana de Nafion $\circledast$}

O tratamento da película de Nafion ${ }^{\circledR} 117$, a partir da sua forma industrializada, consiste em retirar impurezas provenientes do manuseio do polímero, imersão em meio ácido para que a membrana assuma sua característica de condutividade protônica e manutenção da hidratação após esse processo.

SAKTHIVEL et al [20] utilizam solução aquosa a 3\% de peróxido de hidrogênio $\left(\mathrm{H}_{2} \mathrm{O}_{2}\right)$ a $100^{\circ} \mathrm{C}$ por uma hora, para a remoção de impurezas. Em seguida, tratam a membrana em água destilada a $100^{\circ} \mathrm{C}$ por duas ou três vezes para a remoção de excesso de $\mathrm{H}_{2} \mathrm{O}_{2}$.

Para o tratamento de imersão em ácido, alguns autores [14-15] utilizam processo com ácido nítrico. ANANTARAMAN et al [15] fazem uso da seguinte sequência: imersão da membrana em solução de $30 \%$ de ácido nítrico em ebulição, por aproximadamente 30 minutos, lavagem com água destilada e finalmente, imersão em água destilada em ebulição por mais 30 minutos. Entre certos autores, as concentrações das soluções empregadas e tempos variam, porém, basicamente, os métodos são equivalentes.

Existem também autores que realizam o tratamento com ácido sulfúrico. SAKTHIVEL et al [20] tratam a membrana em imersão em solução $1 \mathrm{M} \mathrm{H}_{2} \mathrm{SO}_{4}$ por 2 horas em temperatura ambiente, após o tratamento de limpeza já citado. Em seguida removem o excesso de ácido com lavagem da membrana em água bidestilada repetidamente.

$\mathrm{O}$ tratamento em ácido induz trocas iônicas na membrana, fazendo-a assumir a sua forma protônica. Dessa maneira, a membrana hidratada adquire sua condutividade protônica necessária à montagem eletroquímica da célula a combustível ou sensor de hidrogênio.

Após o tratamento com ácido, é preciso acondicionar a membrana tratada de forma que ela mantenha sua hidratação. Acondicionamento em água destilada de forma que a membrana mantenha suas características mecânicas é normalmente utilizado.

\section{APLICAÇÕES EM SENSORES DE HIDROGÊNIO}

Dado que os polímeros condutores de prótons são amplamente empregados como eletrólito sólido em pilhas a combustível, é natural concluir que seu uso como alternativa ao eletrólito líquido em sensores eletroquímicos de hidrogênio seria viável.

Diversos autores citados neste trabalho estudaram a utilização de eletrólitos poliméricos sólidos na detecção de hidrogênio $[\underline{4}, \underline{5}, \underline{9}, \underline{10}, \underline{14}, \underline{20}]$.

$\mathrm{Ng}$ e Newman [5] utilizam o processo de hidratação da membrana de Nafion ${ }^{\circledR} 117$ em ácido sulfúrico. As curvas de permeação de hidrogênio apresentaram resultados divergentes do ensaio de Devanathan e Stachursky [6], tido como experimento de controle. Os desvios encontrados foram atribuídos à formação de óxidos na superfície dos eletrodos ou à descontinuidade da superfície de contato membranaeletrodo. Todavia, os resultados demonstram a possibilidade do uso do Nafion ${ }^{\circledR}$ como alternativa para sensores de hidrogênio permeado em membranas metálicas.

Já SAKTHIVEL et al. [20] testaram um sensor de gás hidrogênio usando o Nafion ${ }^{\circledR}$. O sensor obteve sensibilidade adequada ao hidrogênio gasoso em diferentes pressões parciais, resultando em curvas de correntes proporcionais à quantidade de hidrogênio ensaiada. Estes autores também se utilizam de técnica de hidratação da membrana polimérica que faz uso do ácido sulfúrico, após tratamento de limpeza com peróxido de hidrogênio. Da mesma maneira, HONG et al. [14] testaram sensores de gás hidrogênio usando Nafion ${ }^{\circledR}$, com resultados positivos. Porém, estes autores usaram o ácido nítrico para tratar o polímero.

Além da detecção de hidrogênio, OPEKAR et al. [21] discutiram diversas aplicações de sensores baseados em eletrólitos sólidos de Nafion ${ }^{\circledR}$ para diversos tipos de substâncias, concluindo que o uso deste polímeros como eletrólito sólido em sensores eletroquímicos variados é uma solução viável.

\section{CONCLUSÃO}

Primeiramente, a hipótese de que a aplicação de membranas poliméricas em sensores eletroquímicos de permeação de hidrogênio em metais é viável pôde ser constatada nesta revisão bibliográfica. Foi demonstrado que autores propuseram e testaram a aplicação dos polímeros condutores de prótons neste tipo de sensor, obtendo resultados satisfatórios.

Pôde-se igualmente verificar que membranas poliméricas usadas como eletrólito sólido possuem características e propriedades, como a condutividade protônica, por exemplo, fortemente dependentes do modo como a membrana é tratada antes do seu emprego. Resumidamente, a hidratação da membrana é o processo mais importante a ser observado, dado que a condutividade protônica é bastante dependente da quantidade de água presente na estrutura polimérica.

Os autores estão em fase de desenvolvimento de um sensor eletroquímico de permeação de hidrogênio empregando eletrólito sólido de membrana polimérica. Para esta concepção, será utilizada uma 
membrana de Nafion ${ }^{\circledR}$, a qual deve ser preparada de acordo com os procedimentos descritos nesta revisão bibliográfica, com o objetivo de se obter um eletrólito sólido com propriedades adequadas de condutividade protônica, durabilidade e confiabilidade.

\section{BIBLIOGRAFIA}

[1] CORREA, L. A., Processo de Medição de Hidrogênio Permeado em Estrutura Metálica e Aparelho Correspondente. BR n. PI9905430-2, 1999.

[2] JAMBO, H. C. M., Corrosão - Fundamentos, Monitoração e Controle., Rio de Janeiro, Ciencia Moderna, 2008.

[3] JAMBO, H. C. M., Desenvolvimento de Sensor Eletroquímico para Detecção de Hidrogênio, Rio de Janeiro, Tese de Doutorado., PPGEMM/COPPE/UFRJ, 1995.

[4] SMITH, R, D., et al., “Advances in Low Cost Hydrogen Sensor Technology”. In: Advances in Hydrogen Energy, New York, Kluwer Academic Publishers, 2002.

[5] NG, H. C., NEWMAN, R. C., "Amperometric hydrogen permeation measurement in iron using solid polymer electrolyte fuel cells", Corrosion Science, v. 47, n. 5, pp.1197-1210, 2005.

[6] DEVANATHAN, H. A. V., STACHURSKI, Z. A., "Technique for the Evaluation of Hydrogen Embrittlement Characteristics of Electroplating Bathe"., J. Eletrocehm. Soc., v.10, n. 8, pp. 886-890, 1963.

[7]. YAMAKAWA, K., TSUBAKINO, H., YOSHIZAWA, S. Eletrochemical Monitoring of Hydrogen in Steel Exposed in Corrosive Environment, Nikko, Japan, Ed. Nace, 1986.

[8] MANSFELD, F., JEANJAQUET, S., ROE, D. K., "Barnacle Electrode Mesurement System for Hydrogen in Steels", Materials Performance, v. 21, pp.35-38, 1982.

[9] LYON, S. B., FRAY, D. J., "Detection of hydrogen Generated by Corrosion Reactions Using Solid Electrode Probe", Materials Performance, v. 23, pp. 23-25, 1984.

[10] YÉPES, O. V. J. R., “Apparatus and method for monitoring hydrogen”. USNN 09/119.008.

[11] KIM, Y. S., PIVOVAR, B. S., "Polymer Electrolyte Membranes for Direct Methanol Fuel Cells". In: Advances in Fuel Cells, v. 1, [s.1.], [s.n.], p. 187-234, 2007.

[12] DUPONT. DuPont. Disponivel em: 〈http://www2.dupont.com/FuelCells/en_US/products/nafion.html〉. Acesso em: agosto 2010.

[13] BEATTIE, P. D., et al., "Ionic conductivity of proton exchange membranes", Jor. Electroanal. Chem., v.503, n.1-2, pp. 45-56, 2001.

[14] HONG, Y., OH, S. M., "Fabrication of polymer electrolyte fuel cell (PEFC) H 2 sensors". Sensors and Actuators B, v. 32, n.1, pp. 7-13, 1996.

[15] ANANTARAMAN, A. V., GARDNER, C. L., "Studies on ion-exchange membranes. Part 1 - Effect of humidity on the conductivity of Nafion". Jor. Electroanal. Chem, v. 414, n. 2, pp. 115-120, 1996.

[16] GAVACH, C. et al., "AC impedance investigation of the kinetics of ion transport in

Nafion perfluorosulphonic membranes", Jor. Membrane Sci., v. 45, pp. 37-53, 1989.

[17] BARBIR, F. "Main Cell Components, Materials Properties and Processes". In: PEM Fuel Cells, cap. 4, [S.1.], [s.n.], p. 73-113, 2005.

[18] COLLIER, A., et al. "Degradation of polymer electrolyte membranes", Inter. Jor. of Hydrogen Energy, v. 31, n.13, pp. 1839-1854, 2006.

[19] MATOS, B. R., Preparação e Caracterização de Eletrólitos Compósitos Nafion - TiO2 para Aplicação em célula a Combustível de Membrana de Troca Protônica, Sao Paulo, Dissertação de M.Sc., Universidade de São Paulo, São Paulo, SP, Brasil, 2008.

[20] SAKTHIVEL, M., WEPPNER, W., "Development of a hydrogen sensor based on solid polymer electrolyte membranes”. Sensors and Actuators B, v. 113, n. 2, pp.998-1004, 2006.

[21] OPEKAR, F.; STULIK, K. "Electrochemical sensors with solid polymer electrolytes". Anal. Chimica Acta, v. 385, n. 1-3, pp. 151-162, 1999. 